\title{
Analyzing of Reduction Process of Urban Open Spaces in Process of Cities Development with Emphasis on Crisis Management in Tehran Metropolis
}

\author{
Hamidreza Saremi ${ }^{1}$, Maryam Ebrahimpour ${ }^{1,2} \&$ Seyed Massoud Saeedi ${ }^{3}$ \\ ${ }^{1}$ Architecture Department, Science and Research branch, Islamic Azad University, Boroujerd, Iran \\ ${ }^{2}$ Department of Art and Architecture, Science and Research branch, Islamic Azad University, Boroujerd, Iran \\ ${ }^{3}$ Faculty of Art, Tehran University, Iran \\ Correspondence: Maryam Ebrahimpour, Science and Research branch, Islamic Azad University, Boroujerd, Iran. \\ Tel: 93-8303-6876. E-mail: ebrahimpourmaryam20@yahoo.com
}

Received: July 4, 2012 Accepted: August 14, 2012 Online Published: August 28, 2012

doi:10.5539/jsd.v5n9p130 URL: http://dx.doi.org/10.5539/jsd.v5n9p130

\begin{abstract}
Urbanism is effective science in order to reduction damages while accruing disaster. Indeed, urbanism is important in term of natural crisis due to have key role in physical development process.

Today one of the most important issues in Tehran metropolis is shortage of usable open spaces in crisis conditions because there is proportion between built spaces, building density and usable open spaces in crisis conditions. It is clearly that could be used from open spaces in crisis conditions as relief base and temporary accommodation.

The main issue in order to studying in dynamic systems is reduction process of urban open spaces with usable in crisis conditions. So in this research have been defined new mechanisms and policies in order to modification of destructive mechanism by studying of effective mechanisms and identifying cause-effect structure.

In this study, at first was determined system boundary and effective endogenous and exogenous variables. Then, was studied reference variable behavior. After that were determined dynamic assumptions and was prepared conceptual model and cause-effect diagrams. At finally, modeling was performed by definition of parameters and structuring of dynamic theories in "Vensim PLE" Software for 20 years periods. The obtained model was tested in extreme conditions.

Analyzing of reduction process of urban open spaces in process of cities development in Tehran metropolis is the purpose of this research. The research method is analysis - descriptive. Also data collected is documents - field. The results show that will be controlled reduction process of urban open spaces with usable in crisis conditions in Tehran metropolis by modification of destructive mechanisms also using policies that associated with key variables.
\end{abstract}

Keywords: open spaces, development, crisis, modeling, Tehran

\section{Introduction}

\subsection{Introduce the Problem}

Urban open spaces are one of the importance Infrastructure that could be used them in process of crisis management as effective and efficient spaces in order to reduce the damage of disaster (earthquake, volcano, flood, etc.). We can use these spaces, while happening crisis as relief base; also we use them as temporary accommodations.

Iran has been located in dangerous place due to geological conditions and geographic location. Thus, are accruing damages due to natural disaster such as flood and earthquake.

These are factors that increase harmful effects of disasters such as: construction in high-risk areas, disregard to strength and proper distribution of buildings and vital installations, existence of heterogeneous and urban old structures and etc. Also Lack of awareness and readiness of the people and authorities are double factor in aggravating deaths and injuries disasters. 
While accruing crisis, will appear physical damage in various form in urban environment due to instability of elements and urban areas in crisis (earthquake, flood) in short time.

In these situation, not only rescue group and army is not enough to save residents but also should be used various sciences and knowledge such as Architecture \& Urbanism and crisis management in order to reduce human damages, critical and sensitive equipment, infrastructure services and critical needs. Today in many of cities in country especially in Tehran are reduced open spaces due to uncontrolled construction of building in cities. The reduction of green, open, sport spaces could be studied during in 40 years ago in Tehran. Although in this period there are urban development plans but these natural potencies and advocacy tools damage more than other times. On the other hand, there are low per capita of green space and sport lands, also imbalance in distribution of function in urban development plans have been led to that is accursed a great shortage such spaces (open space, green space) in many of compact and central area of city.

Conversation process of green space, open space and sport space to commercial and office spaces are more faster than conversation other spaces to green $\&$ sport spaces.

According to studies from 2004 to 2005 , over 600 cases of open and green spaces have changed to residential and commercial land use legally (Behzaffar, 2009). According to status quo studies of Tehran comprehensive plan, totally the area of green space is 4463 acre in 1986. This land use has been distributed imbalance in city. The area of land use is 1486 acre in 5 districts of Tehran while the area of land use in $7 \& 10$ districts were only $2 \& 3$ acre. In these periods $1 \& 7$ districts had $40.6 \& 0.07$ per capita (Atak, 1992).

So it is necessary that is predicted these open spaces to preventing reduce these spaces, also creating balance in order to improving quality of urban environment and preparation for possible crisis (Figures $1 \& 2$ ).

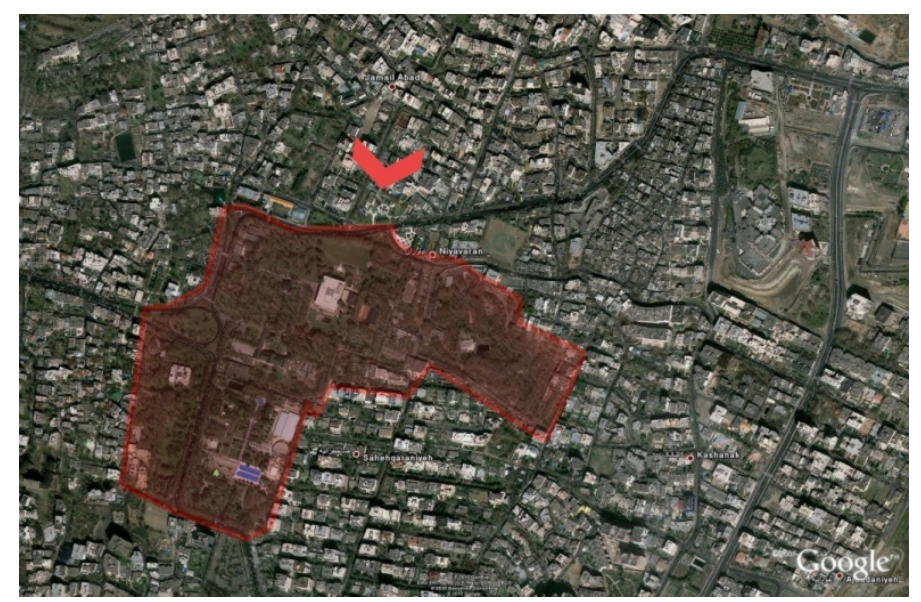

Figure 1. There are some green spaces in density \& organic tissue of Tehran

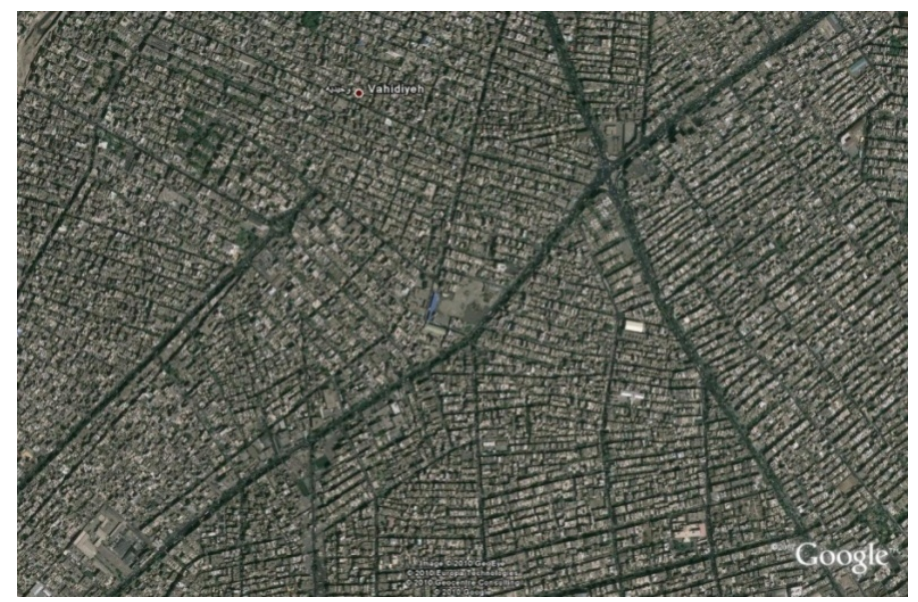

Figure 2. In area of central and east of Tehran, despite the compactness and high density there isn't open space 


\section{Method}

This study has been done in five steps that they are: 1) Studying of reduction process of urban open spaces in Tehran development process, 2) Structuring dynamic variable, 3) Formulation of simulations models, 4) Experiment, 5) Design and review of policies.

\subsection{Studying of Reduction Process of Urban Open Spaces in Tehran Development Process}

Have been mentioned basics variables for creating models and identifying effective mechanisms in reducing Tehran open spaces in the last 40 such as:

1) The areas of urban open spaces

2) The areas of urban spaces that has been built

3) Population (Table 1)

Table 1. The number of changes green space, Public Park, sport \& recreation land uses in different commissions than other land uses

\begin{tabular}{|c|c|c|}
\hline sport \& recreation & green space, Public Park & Land use \\
\hline 1 & 28 & $\begin{array}{l}\text { Coordination council ( comprehensive plan that adapted in } \\
\qquad 1968 \text { to } 1977 \text { ) }\end{array}$ \\
\hline 18 & 128 & $\begin{array}{c}\text { Plan and assessment council } \\
\text { 1986- } 1977\end{array}$ \\
\hline 48 & 382 & Commission of 51 ( after 1977 ) \\
\hline 67 & 538 & total \\
\hline
\end{tabular}

The areas of urban open spaces: This variable is as reference variable. Other variables are considered with formation increasing and decreasing mechanisms in changing of amount urban open spaces during the time. So has been considered as state variable (Figure 3).

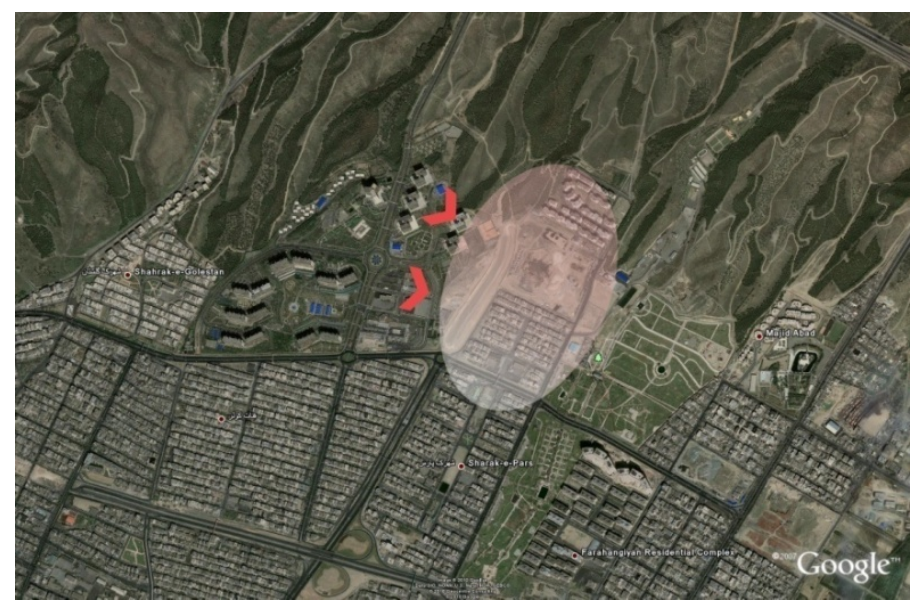

Figure 3. Sample of vacant lands that have been built in north east of Tehran

The areas of urban spaces that have been built: This variable is one of the most important main variables that affect on reference variable changes. For example by changing built areas, change other variable such as sail density. Therefore is observed changing the amount of urban open spaces. Population: The population variable is studied as state variable. By changing of population, change demand for construction and service and residential levels. So change reference variable (Figure 4) (Table 2). 


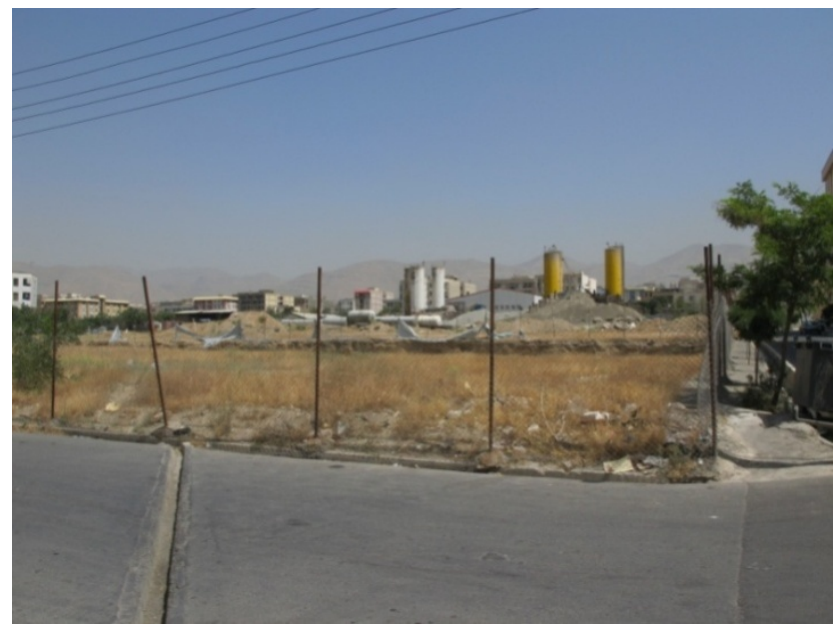

Figure 4. In last years have been built some lands that usable in temporary condition

Table 2. Effective variables

\begin{tabular}{ccc}
\hline Flow variables & Auxiliary variable & State variable \\
\hline Sailing density & Lake of supervision in construction & The price of land \\
Migration to city & Management changing & population \\
Producing automobile & Marginalization & Municipal budget \\
Demand for construction & lake of facilities in other city & The areas of urban open spaces \\
Widening the street & The lake of comprehensive plan & \\
\hline
\end{tabular}

\subsubsection{Considered Time Period}

Social, economic and physical factors that have been considered in conceptual model problem show that the highest changes have been in recent 40 years ago. So, in this research in order to creating corrective mechanisms in studied system has been considered twenty - year period as standard ratio due to lack of access to statistic this period, on the other hand reduction process of urban open spaces are different.

\subsubsection{Reference Variable Behavior}

The main variable is usable open space in crisis conditions or spaces that have passive defense potential. This variable is assessed as state variable because the amounts of these areas are measurable in different times. State variable in studied period have faced reduction process. According to Tehran satellite images, the amount of urban open spaces decrease by using in temporary condition approach.

\subsection{Structuring Dynamic Variable}

In this section after identifying effective variables in problems and effective mechanism in behavior reference variable create dynamic variables. Thus at first is determined system boundary. After that has been defied cause - effect conceptual graph (Table 3).

Table 3. Determining of System Boundary

\begin{tabular}{ccc}
\hline Variables that hasn't been considered & Exogenous variables & Endogenous variables \\
\hline loans granted & Migration to city & Sailing density \\
Construction costs of government & lake of facilities in city & Demand for construction \\
Marginalization & Increasing automobile & Price of land \\
Management changing & Improving urban utility & Population \\
\hline
\end{tabular}


Endogenous variables: These variables are related to internal characterizes of studied system (the area of Tehran). For example the population and demand for construction are related to social characterize also sailing density and price of land are related to economic characterized. These variables have been considered in structuring dynamic variables. Exogenous variables: These variables are effective from social and economic factors that aren't related to internal characterize of system. For example some factors such as migration to city, lake of facilities, and the urban utility are affected by external policies and decisions.So with definition of endogenous \& exogenous variables is specified system boundary as dynamic relations.

\subsubsection{Conceptual Graph}

In conceptual graph have been defined three effective factors on reference variable. These factors are social (population), built spaces and open spaces. Open spaces are include large, medium and small parks, squares, green spaces and other space that are used in crisis conditions. Also the built spaces are construction activities and physical interventions in urban fabric that influence on urban open spaces.

Social factors have been composed some variables such as: migration to city, population, Demand for construction and neglect to keep urban green spaces (Bahraini, 1991) (Figure 5).

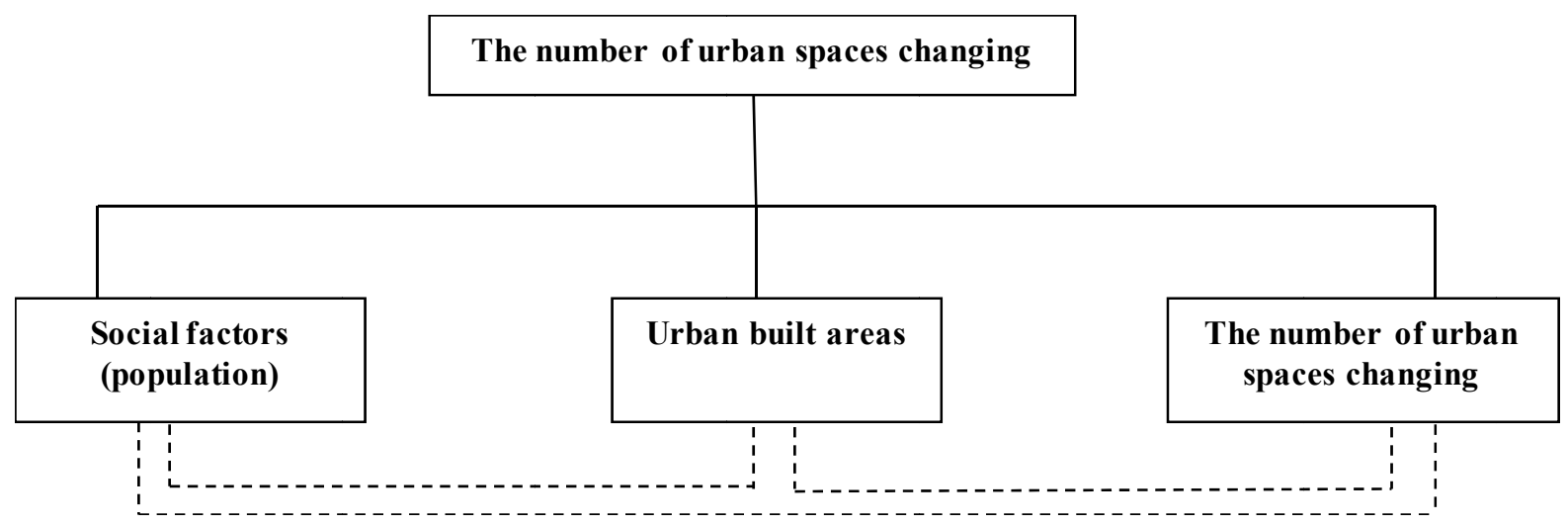

Figure 5. Conceptual graph of main variables relations

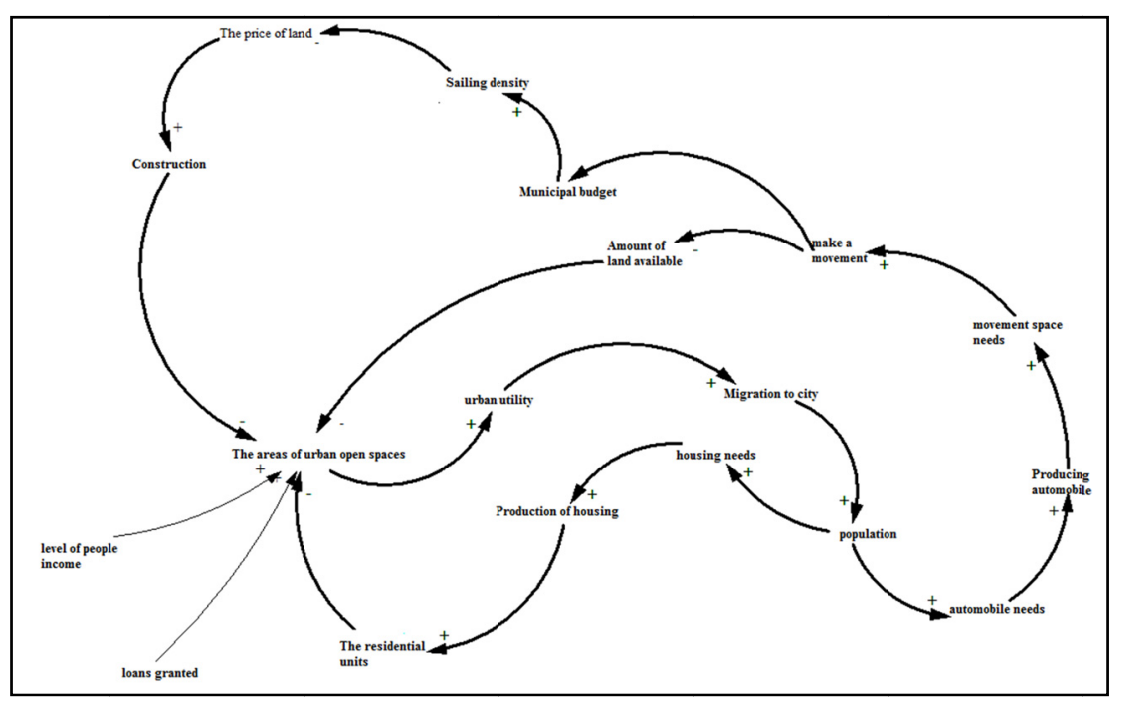

Figure 6. Cause - effect graph

According to above graph, can be seen two main rings:

In first ring, the population creates demand for increasing of automobile number. So we need travel spaces. Thus is created construction process. These processes are strengthened with decreasing of municipal budget also sailing of density. At finally reduce urban open spaces. On the other hand by increasing of urban open spaces improve urban desirability and increase population. So previous ring is repeated in order to using open spaces 
and reducing per capita.

Also in second ring, increasing of population is led to need for housing production again. By increasing of construction are reduced urban open spaces. On the other hand in this ring by increasing open areas is activated population growth and demand for construction again.

\subsection{Formulation of Simulations Models}

\subsubsection{Determines Structure and Modeling Rules}

The structures of model consist of effective variables such as population, built areas and urban open spaces areas. Furthermore have been considered auxiliary variables such as (income people - loans granted) in order to definition of logical relations of system.

\subsubsection{Estimated Parameters, Relations and Initial Conditions}

According to existing condition and corrective polices for controlling destructive mechanisms and preventing reduction of urban open spaces was designed model that consist of: 1) Urban population, 2) The number of built spaces in city, 3) the number of open spaces in city (Figure 7).

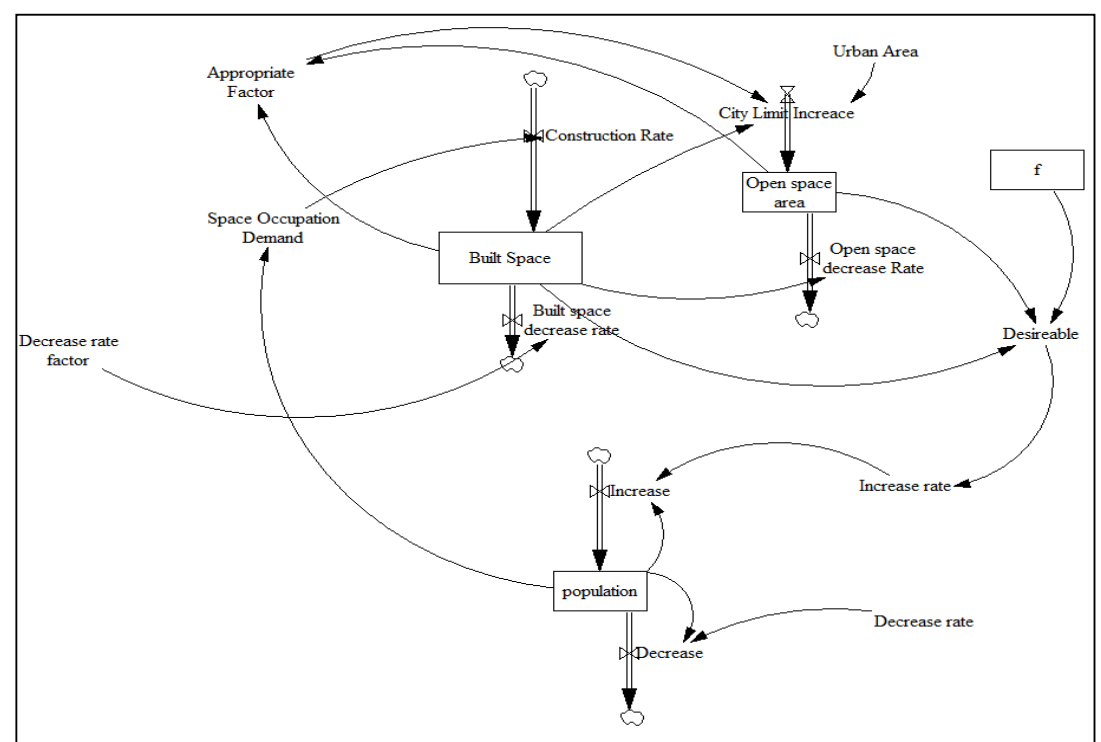

Figure 7. Flow graph

The distribution of main land use is one of the most important issues in order to planning of future in cities. So should be balanced between allocated space with Communication of network system and open space system in future. The distribution of land uses depend on especial condition in city and quality of planning.

Generally, the areas of residential spaces and element services in medium urban density are in Table 4.

Table 4. The composition of main land uses

\begin{tabular}{cc}
\hline $\begin{array}{c}\text { The kind of space and } \\
\text { land use }\end{array}$ & Percent of total area of city \\
\hline Residential spaces & 50 \\
Roadway spaces and & \\
pedestrian routes & 25 \\
Sport and green spaces & 15 \\
Other services spaces & 10 \\
\hline
\end{tabular}

In this model has been tried that is created balance between the areas of built spaces and the areas of urban open spaces. It means: 


\section{Open Space/ City Space $=0 / 4$}

So by considering auxiliary variables as appropriate Factor while increasing urban full spaces will be added to urban empty spaces constantly and will be controlled the reduction process of these spaces .

Thus, appropriate Factor is formulated as follow:

\section{Ap Factor $=$ Built Space - Open Space}

The areas of urban open spaces have been limited by increasing urban open spaces. Also, the increasing ratios of built spaces aren't fixed (Figure 8) (Table5).

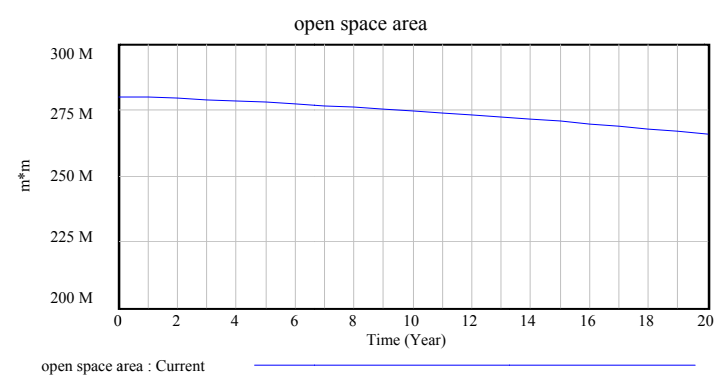

Figure 8. Predication changing of urban open spaces reductionduring in 20 years periods

Table 5. Predication changing of urban open spaces reductionduring in 20 years periods

\begin{tabular}{|c|c|c|}
\hline Tim & & "open space area" Runs \\
\hline 0 & Current & $2.8 e+008$ \\
\hline 1 & & $2.8 \mathrm{e}+008$ \\
\hline 2 & & $2.795 e+008$ \\
\hline 3 & & $2.78978 \mathrm{e}+008$ \\
\hline 4 & & $2.78434 \mathrm{e}+008$ \\
\hline 5 & & $2.77866 \mathrm{e}+008$ \\
\hline 6 & & $2.77274 \mathrm{e}+008$ \\
\hline 7 & & $2.76656 \mathrm{e}+008$ \\
\hline 8 & & $2.76011 \mathrm{e}+008$ \\
\hline 9 & & $2.75339 \mathrm{e}+008$ \\
\hline 10 & & $2.74638 \mathrm{e}+008$ \\
\hline 11 & & $2.73906 \mathrm{e}+008$ \\
\hline 12 & & $2.73143 e+008$ \\
\hline 13 & & $2.72348 \mathrm{e}+008$ \\
\hline 14 & & $2.71518 \mathrm{e}+008$ \\
\hline 15 & & $2.70653 e+008$ \\
\hline 16 & & $2.6975 e+008$ \\
\hline 17 & & $2.6881 \mathrm{e}+008$ \\
\hline 18 & & $2.67829 e+008$ \\
\hline 19 & & $2.66807 e+008$ \\
\hline 20 & & $2.65741 \mathrm{e}+008$ \\
\hline
\end{tabular}

In order to estimation of added full spaces in city for every person that has been added to populations, has been used from variable that it is according to global standards and urban spaces quality in Tehran city. Indeed for every person that has been added to populations, will add 50 square meters to urban built spaces (www.pps.org).

$$
\text { Space Occupation Demand }=\text { Population } * \mathbf{5 0} \mathbf{~ m}^{\mathbf{2}}
$$

There for, construction rate increase by increasing built spaces (Figure 9) (Table6). 


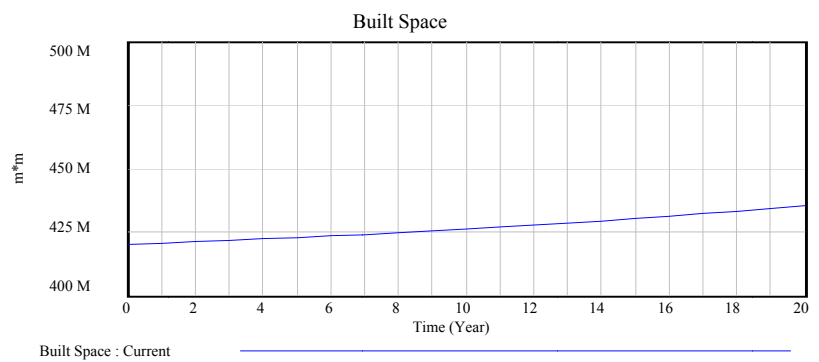

Figure 9. Predication amount of urban built areasduring in 20 years periods

Table 6. Predication changing of urban built areas during in 20 years periods

\begin{tabular}{|c|c|c|}
\hline \multicolumn{2}{|c|}{ Time (Year) } & "Built Space" Runs \\
\hline 0 & Current & $4.2 \mathrm{e}+008$ \\
\hline 1 & & $4.205 e+008$ \\
\hline 2 & & $4.21022 \mathrm{e}+008$ \\
\hline 3 & & $4.21566 e+008$ \\
\hline 4 & & $4.22134 \mathrm{e}+008$ \\
\hline 5 & & $4.22726 e+008$ \\
\hline 6 & & $4.23344 e+008$ \\
\hline 7 & & $4.23989 e+008$ \\
\hline 8 & & $4.24661 \mathrm{e}+008$ \\
\hline 9 & & $4.25362 \mathrm{e}+008$ \\
\hline 10 & & $4.26094 e+008$ \\
\hline 11 & & $4.26857 e+008$ \\
\hline 12 & & $4.27652 \mathrm{e}+008$ \\
\hline 13 & & $4.28482 e+008$ \\
\hline 14 & & $4.29347 e+008$ \\
\hline 15 & & $4.3025 e+008$ \\
\hline 16 & & $4.3119 e+008$ \\
\hline 17 & & $4.32171 e+008$ \\
\hline 18 & & $4.33193 e+008$ \\
\hline 19 & & $4.34259 e+008$ \\
\hline 20 & & $4.3537 e+008$ \\
\hline
\end{tabular}

In proposed model, the state variable of population is influenced by increased and decreased rate of them. In this research have been considered the urban natural growth rate. Also, the population has been assumed 7 millions in the base year'.

One of the factors of urban population growth rate is, improving of urban desirable indicator.

This indicators have been considered in formulate of problem as function of open space areas. It means;

\section{F (Open Space / Built Space)}

Therefore the population growth rate variable has been defined as follow: (Figure 10) (Table 7).

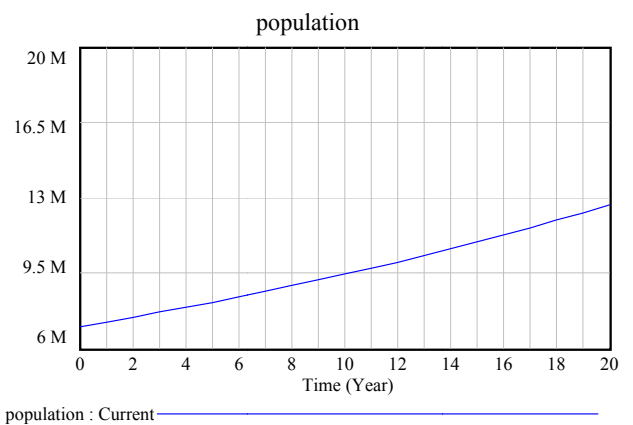

Figure 10. Predication urban population growth of tehran in 20 years period 
Table 7. Predication urban population growth of tehran in 20 years period

\begin{tabular}{|c|c|}
\hline \multicolumn{2}{|c|}{ Time (Year) "population" Runs } \\
\hline 0 & Current $7 \mathrm{e}+006$ \\
\hline 1 & $7.2205 \mathrm{e}+006$ \\
\hline 2 & $7.44193 e+006$ \\
\hline 3 & $7.66571 e+006$ \\
\hline 4 & $7.89568 \mathrm{e}+006$ \\
\hline 5 & $8.13255 e+006$ \\
\hline 6 & $8.37653 e+006$ \\
\hline 7 & $8.62783 e+006$ \\
\hline 8 & $8.88666 e+006$ \\
\hline 9 & $9.15326 e+006$ \\
\hline 10 & $9.42786 e+006$ \\
\hline 11 & $9.7107 e+006$ \\
\hline 12 & $1.0002 \mathrm{e}+007$ \\
\hline 13 & $1.03021 \mathrm{e}+007$ \\
\hline 14 & $1.06111 \mathrm{e}+007$ \\
\hline 15 & $1.09295 e+007$ \\
\hline 16 & $1.12574 \mathrm{e}+007$ \\
\hline 17 & $1.15951 \mathrm{e}+007$ \\
\hline 18 & $1.19429 e+007$ \\
\hline 19 & $1.23012 \mathrm{e}+007$ \\
\hline 20 & $1.26703 e+007$ \\
\hline
\end{tabular}

\section{Increase: Population* Increase Rate}

Testing for compatibility with the boundary issue: The endogenous variables behavior has been considered according to definition the internal relations and initial assumptions that are, consistent with reference variable behavior.

\subsection{Experiment}

\subsubsection{Compared with Reference Behavior}

In these models has been tried that the main variable behavior in proposed model compare to reference behaviors such as: increased \& decreased population ratio, migration ratio, producing automobile ratio and urban standards per capita. So some indicators such as increasing of population number or producing of automobile have the same additive effects.

\subsubsection{Sustainability in Extreme Conditions}

By studying of proposed model in 20 years periods, is determined that the main variables behavior in extreme conditions (sudden increased of population) would be appropriated with test period.

\subsection{Design and Review of Policies}

\subsubsection{Identifying Scenarios}

According to problem condition, scenarios are different such as:

\section{a. Increasing or decreasing of population}

Increasing or decreasing of population sets increased rate of construction. Also increased rate of construction is led to decreasing of areas.

\section{b. Increasing or decreasing of automobile number}

By changing in automobile number (increasing or decreasing) - as well as changing of population in proposed model - will be set the amount of full or empty areas in city by using allocation factor.

\section{c. Increased or decreased city limits}

Urban open areas are affected by development of city limits. So, should be decreased migration to city and should be encouraged migration from city with incentive tools. Therefore, the number of population is controlled and the population in formulation of problems is reduction. Thus, the construction is controlled and is created proportion between full $\&$ empty spaces. 
2.5.2 Policies in Order to Correction Destructive Mechanisms and Controlling of Reduction of Reference Variable

Some policies is proposed in order to correction destructive mechanisms and controlling of reduction of reference variable (the amount of urban open spaces) after reviewing the existing conditions and identifying effective mechanisms in creating crisis conditions according to cause-effect graph.

a) According to increasing of population and creating demand for producing residential buildings is decreased the construction process also is reduced urban useful spaces. Therefore, are proposed polities in order to controlling of construction demand from source management and urban population in cause-effect rings. These polities can be included appropriate economic and social leverage that strengthen migration from city.

b) According to additive cause-effect ring, by increasing automobile is increased the need for travel spaces. So, are decreased poetical open spaces. Thus it is necessary that are adapted the amount of automobile with urban population and open spaces until is prevented to widening the streets.

c) In addictive ring that it is observable on cause-effect graph, decreasing of municipal budget is caused to sailing of density. The sailing of density create the next mechanisms in order to decreasing urban open spaces. There for, sailing of density should be replaced by other mechanisms. For example municipal can provide their budget from public funds.

The following results are obtained after running of model according to graphs and output value of main variables:

About the main variable (urban open spaces), the variable graph decrease with moderate gradient, by using of controlling construction policies in 20 years periods. At the begging of 20 years period is started from $2.8 \mathrm{e}+008$ to $2.65741 \mathrm{e}+008$ at finally of period. It show that is controlled, sharp declined of urban open spaces. The proportions between full and empty spaces are 0.4 in 20 year period.

About the stat variable (built spaces) will increase for population growth during time.

Output rate has been considered for built areas due to is controlled by identified factors.

According to graphs and output value after running the model is determined. At the begging of 20 years period is started from $4.2 \mathrm{e}+008$ to $4.3537 \mathrm{e}+008$ at finally of period.

Comparison of this graph with open areas graph show that has been controlled declined of urban open spaces process. Indeed remain stable following relation:

\section{Open Space / Built Space $\approx 0.66$}

\section{Results}

One of the most important issues that should be considered in crisis management is appropriate distributions infrastructure such as: emergency routes, safe open spaces, search and rescue and relief centers and emergency medical centers.

In this research was determined that some policies and macro - economic issues such as, focus resources and facilities in Tehran metropolis have been led to loss of balance between urban open spaces and built spaces in 40 years periods. There are some local policies such as sailing of density by municipal especially in two decade ago that has been led to physical development of city. Thus will be decreased urban open spaces.

Therefore in this study has been created the controlled mechanisms of balance between full and empty spaces. Also we expect that be prevented from reduction process of open spaces and reduction of urban space quality in 20 years periods with definition standard rate of these spaces (according standard of Tehran metropolis, Open Space / Built Space $\approx 0.66$ ).

\section{Reference}

Alpha, A., Consulting, E. (1989). "Tehran comprehensive plan", the first physical studies, Volume IV, Tehran, Department of Housing and Urban Development.

Bahrain, H. (1991). Brasilia 20 years later.Journal of Architecture, 25. Tehran.

Bhzadfr, M. (2009). Urban projects and programs. Tehran, nashr publication.

Chermayeff, S. \& Alexander, C. (1992). Social and private life, translated by M. Mozayeni, Tehran University, Tehran.

Lynch, K. (1958). Environmental Adaptability. Journal of the American institute of planners, 24. 
http://dx.doi.org/10.1080/01944365808978281

http://www.googleearth.com

http://www.pps.orgUrban Open Spaces

Pakzad, J. (2007). Guideline of Urban Spaces design in Iran. Tehran, Department of Housing and Urban Development.

Partoy, P. (1995). Evaluation of barriers, restrictions, and reciprocity in the implementation of measures to reduce vulnerability to earthquakes. Second International Conference on Earthquake Engineering, International Institute of Seismology, Tehran.

\section{Notes}

Note 1. Commission of 5 has been created $80^{\text {th }}$ decade. In Iran has been decided about urban issues such as comprehensive plan in this commission.

Note 2. In comprehensive plan of Tehran has been predicted the population of Tehran will be 8.65 million in 1405 . 